WORKING PAPER NO. 96-17

PUBLIC VERSUS PRIVATE DEBT:

CONFIDENTIALITY, CONTROL, AND PRODUCT MARKETS

\author{
Mitchell Berlin \\ Federal Reserve Bank of Philadelphia \\ and \\ Alexander W. Butler \\ Indiana University
}

August 1996

We thank Greg Udell, Patricia Wilson, and participants at the 1995 FMA meetings for helpful comments and discussions. We are responsible for any mistakes that remain. The views in this paper are not necessarily those of the Federal Reserve Bank of Philadelphia or the Federal Reserve System. 


\title{
PUBLIC VERSUS PRIVATE DEBT: CONFIDENTIALITY, CONTROL, AND PRODUCT MARKETS
}

\begin{abstract}
We examine a firm's choice between public and private debt in a model where the firm's financing source affects its product market behavior. Two effects are examined. When firms' risk-taking decisions are strategic substitutes, debt financing leads to excessively risky product market strategies (as in Brander and Lewis' (1986) Cournot oligopoly with debt). Lender control through restrictive covenants--which is characteristic of private debt--can commit the firm to reduce aggressiveness in product markets and increase expected profits. This is the monitoring effect. On the other hand, private debt reduces the amount of public information about a firm that becomes available to its competitors. This is the confidentiality effect. When firms' risktaking decisions are strategic substitutes, firms prefer to precommit to communicate idiosyncratic private information about costs or demand. By choosing public debt, a firm is able to precommit to communicate private information. The choice between public and private debt depends on the relative weights of the monitoring and confidentiality effects.
\end{abstract}




\section{Introduction}

The apparent decline in banks' role in financing firms and the relative increase in the use of public debt has increased researchers' interest in the determinants of firms' choice between public and private debt. Many papers--including this one--view banks as specialists in monitoring and controlling risk-taking by firms. In this view, a greater reliance on public debt increases firm discretion and agency costs. (See Bhattacharya and Thakor (1993) for an extensive review of this literature.) Another effect of relying on public securities is that the firm cannot maintain the same level of confidentiality about its business affairs as when its financing sources are private. Legal reporting requirements, evaluations by rating agencies, and evaluations by analysts who keep close tabs on the firm are all avenues for the dissemination of information about a firm that sells public securities. While the main intended consumers of this information are the firm's investors, this information is also available to the firm's competitors. Thus, following a suggestion by Campbell (1979), some researchers have highlighted the confidentiality of private debt as an important determinant of a firm's choice of financing source. (See Bhattacharya and Chiesa (1995) and Yosha (1995)).

In this paper, we explore the interplay between two factors--the monitoring effect and the confidentiality effect--in a firm's choice of financing source. Specifically, we examine a Cournot duopoly in which firms are debt financed. In this setting, introduced by Brander and Lewis (1986), debt financing leads the competitors to choose overly aggressive and risky business strategies. As noted by Brander and Lewis, firms would often benefit if they were controlled by their creditors, and this is the role of banks in our model. A bank exercises partial control over its borrower via covenants, which give the bank some power to restrict aggressive 
(and risky) output strategies, especially when agency problems are most severe. Thus, bank debt serves as a credible commitment device to reduce aggressive product market strategies. This is the monitoring effect of bank debt, which tends to promote a preference for bank debt. ${ }^{1}$

Following Campbell (1979), most researchers have viewed the confidentiality of private debt as a potential advantage for a firm choosing between public and private debt. ${ }^{2}$ However, the industrial organization literature (e.g., Gal-Or (1986), Shapiro (1986), and Vives (1985)), as well as a historical parade of competing firms that have used devious means to overcome legal restrictions on sharing information, suggests that confidentiality may also be costly. A Cournot competitor that will learn something privately about its own costs would prefer to precommit to share this information with its competitors--whether or not its competitors reciprocate. ${ }^{3}$ In our model, public debt is a mechanism that commits firms to share private information credibly, while private debt commits the firm to keep this information confidential. This is the confidentiality effect of private debt, which tends to reduce a firm's preference for private debt.

It is the tradeoff between the benefits of monitoring and the costs of confidentiality that determines whether firms choose private or public debt in our model. The terms of the tradeoff are determined by a small number of potentially observable factors. The first factor is the

${ }^{1}$ Going beyond the Cournot example, benefits of creditor control arise whenever firms' risk-taking decisions are strategic substitutes. Thus, the idea is more general than the Cournot setting.

${ }^{2}$ This is the viewpoint of both Bhattacharya and Chiesa (1995) and Yosha (1995).

${ }^{3}$ This is a result that has been established in many different contexts. The intuition underlying the result will carry over to any model in which firms compete in strategic substitutes. Further, the private information need not be about costs. The benefits of sharing information arise as long as the information is firm specific. 
likelihood of a market downturn, in our model such a downturn is due to decline in the demand for all competitors' products. Public debt is more attractive when the probability of a contraction in demand is small. The second factor is the probability that a firm will be the low cost producer, which is natural to interpret as the probability of technological advance. The higher the probability of technological advance in the industry, the greater the relative preference for public debt.

We proceed as follows. In Section 1, we present the model. In Section 2, we focus on informational effects in isolation by examining internally financed firms. In Section 3 we present comparative statics results relating the firm's choice of financing source to potentially observable characteristics of the market. In the final section we conclude.

\section{The Model}

Although we will examine a highly specialized variant of the model in this paper, it is convenient to describe the model in more general terms at the outset. There are two firms, indexed by $\mathrm{j}=1,2$, and three periods.

\subsection{The timing of production}

The firms are Cournot competitors producing identical goods with constant marginal costs. In period 0 , firm $\mathrm{j}$ invests $\mathrm{I}_{\mathrm{j}}$ dollars to finance new plant and equipment. Initially, each firm is uncertain both about its own cost of production and about the size of total demand in the market. At the beginning of period 1 , firm $j$ learns its marginal cost $c_{j} \in\left\{c_{j L}, c_{j H}\right\}$, with $c_{j H}>c_{j L}$, and the probability of a low cost realization $\left(\mathrm{p}_{\mathrm{j}}\right)$ is assumed independent across firms. One interpretation of this random variable is that a reduction in costs is the uncertain outcome of past 
$R \& D$ expenditures. Then, higher values of $\mathrm{p}_{\mathrm{j}}$ indicate a market in which technological progress is rapid.

After firms learn their marginal costs, communication between competitors may occur; whether any communication occurs depends on the firms' financing choices (as described below). After any communication between firms, but before period 2 , firm $\mathrm{j}$ commits to produce output level $\mathrm{q}_{\mathrm{j}}\left(\mathrm{c}_{1}, \mathrm{c}_{2}\right)$.

At the beginning of period 2, total demand is determined. Specifically, the intercept, a, of the inverse demand curve,

$$
P(Q)=a-q_{1}-q_{2},
$$

is a random variable realized at the beginning of period 2 with $a \in\left\{a_{b}, a_{g}\right), a_{g}>a_{b}$. The prior probability of a good demand state $\left(a=a_{g}\right)$ is $\varphi$, and the prior probability of a bad demand state (a $=a_{b}$ ) is 1- $\varphi$. Note that the firms cannot condition their output choices on the level of demand, because they have already committed to particular output levels before information about market demand arrives. Production actually takes place in period 2.

\subsection{Financing choices and contracts}

Firms have no internal funds to cover the costs of their initial investments. Although they cannot secure equity financing, they can choose between public and private debt. As a convenient shorthand we will refer to public debt as bonds and private debt as loans. Although many real world firms do actually borrow through a mixture of public and private debt, we will assume that the firm must choose either loans or bonds exclusively. Our interpretation of this assumption is that the distinctive characteristics of private financing--especially confidentiality-essentially disappear when a firm relies on public finance above some (relatively low) threshold 
level.

Loans and bonds differ along two dimensions. First, selling bonds in period 0 commits a firm to communicate its private information about its own costs in period 1, while taking out a loan in period 0 commits the firm to keep its costs confidential. When we say that public debt commits a firm to communicate idiosyncratic information, we have the following ideas in mind. By law, and in light of the need to market the securities to a wide range of investors, firms are forced to reveal information about the uses of the funds. Also, firms that wish to sell public securities must have in place comparatively standardized accounting systems, which substantially ease outside investors' and competitors' ability to interpret firms' cost structures and business prospects. Moreover, the need to sell securities on a continuous basis creates a clientele for information about the firm's affairs and an incentive for professionals to produce such information. Here we include rating agencies and investment analysts. So, even when a firm might wish to hide some information about its prospects, this may be very difficult when the firm is a regular borrower on public debt markets.

Private debt has precisely the opposite effect of committing a firm to keep private information confidential. Even when a firm might wish to communicate information about its prospects, it may be difficult to do so credibly when its accounting systems are opaque and when no network of information producers exists to analyze and interpret information.

The second main difference between loans and bonds is that private lenders, through the use of stringent covenants and the selective renegotiation of covenants, can exercise greater control over the firm than can public bondholders. These features of private debt have been the subject of a large literature, so we will not reiterate the arguments here. (See Bhattacharya and 
Thakor (1993) for an extensive review of this literature.) Formally, we model the difference in the control features of bonds and loans as follows.

Bonds are modeled precisely as in Brander and Lewis (1986). In particular, bondholders have no control over the firm's output decision, which is made in period 1. If the firm's gross revenues in period 2 ,

$$
\mathrm{R}_{\mathrm{j}}\left(\mathrm{c}_{1}, \mathrm{c}_{2}, \mathrm{a}\right) \equiv\left[\mathrm{a}-\mathrm{q}_{1}\left(\mathrm{c}_{1}, \mathrm{c}_{2}\right)-\mathrm{q}_{2}\left(\mathrm{c}_{1}, \mathrm{c}_{2}\right)-\mathrm{c}_{\mathrm{j}}\right] \mathrm{q}_{\mathrm{j}}\left(\mathrm{c}_{1}, \mathrm{c}_{2}\right)
$$

are less than the face value of the bonds, $\mathrm{D}^{\mathrm{p}}$, the firm defaults and the bondholders receive all of the firm's revenues. There are no deadweight bankruptcy costs, so bondholders would never have any incentive to renegotiate with the firm to avoid bankruptcy in our model. ${ }^{4}$

We model bank monitoring and control through covenants in a simple way, which abstracts from many of the interesting bargaining and contract design issues that have been highlighted in previous accounts of debt renegotiations. The bank can observe the firm's costs without error, and high cost realizations are correlated with some measurable accounting item, which is the basis for a restrictive covenant. In fact, we examine a polar case, in which a firm with high costs is always in breach of the covenant restriction and only a firm with high costs is in breach. Thus, the correlation is perfect. As we will see below, high cost states are those in which agency problems are most likely to arise, so optimal covenants would typically target bank interventions in such states.

Any breach of the covenant occurs before the firm chooses its output level, which it does in period 1. If the firm breaches the covenant, the bank makes a single offer to the firm. This

${ }^{4}$ Even with deadweight bankruptcy costs, we may think of the no renegotiation assumption as a stylized way of capturing the difficulties of renegotiations between a firm and public bondholders. 
offer specifies both the output level and distribution of the expected profits between the bank and the firm. For simplicity, and without loss of generality, we assume that the bank captures all of the firm's profits in those states when the covenant is breached.

When the firm's costs are low, there is no breach of contract, and the original loan contract with face value $\mathrm{D}_{\mathrm{j}}^{\mathrm{b}}$ remains intact. We do not permit the firm and its bank to renegotiate contracts unless the firm has breached the covenant. ${ }^{5}$

\subsection{Information structure}

At the outset, both firms know the probability distributions governing marginal costs and market demand. Each also observes how its competitor is financed. At the beginning of period 1, each firm observes privately its own marginal cost realization. If a firm is financed by bonds, this information is communicated immediately to its competitor. If a firm is financed by loans, this information remains confidential.

Each firm can make an inference about its competitor's choice of output levels in period 1, but these output choices are not directly observable. Further, a firm is unable to tell whether its loan-financed competitor has breached its covenant. Given our highly simplified model and stylized loan contract, the formal reason for this assumption is clear. Our assumption ensures that a firm cannot infer its loan-financed competitor's realized costs by observing whether the firm is in breach of the covenant restriction. The economic motivation for this assumption is

${ }^{5}$ In this version of our paper, restricting all bargaining to breach states plays no role, because our parametric assumptions will ensure that the firm voluntarily chooses the valuemaximizing level of output when its costs are low. In more general models, healthy firms and banks might have a joint interest in relaxing covenants even when the firm is not in breach of contract. 
that covenants and breaches of covenant restrictions are noisy in two different ways. First, a firm may be able to cure a breach with relative ease. Thus, breach may be a very imperfect indicator of the bank's power to influence the firm's behavior. Second, a breach of a covenant is a noisy indicator of the depth of the underlying agency problem. A breach will typically lead to monitoring by the bank, which may lead the bank to forgive the default without otherwise affecting the firm's behavior. Introducing either type of noise would complicate the competitor's inference problem without introducing interesting issues.

\subsection{Simplifications and specializations}

In this version of the paper we specialize the model further. First, we assume that only firm 1 has cost uncertainty; that is, $c_{1} \in\{0, c\}$ with $\operatorname{prob}\left(c_{1}=0\right)=p$, while firm 2 has known $\operatorname{costs} c_{2}$, with $c>c_{2}>0$. (Note that there is no loss of generality in assuming that firm 1's lower cost realization is 0 .) Since there is only one source of cost uncertainty--firm 1's costs--we can simplify our notation by writing $\mathrm{q}_{\mathrm{j}}\left(\mathrm{c}_{1}, \mathrm{c}_{2}\right) \equiv \mathrm{q}_{\mathrm{j}}\left(\mathrm{c}_{1}\right)$ and $\mathrm{R}_{\mathrm{j}}\left(\mathrm{c}_{1}, \mathrm{c}_{2}, \mathrm{a}\right)=\mathrm{R}_{\mathrm{j}}\left(\mathrm{c}_{1}, \mathrm{a}\right)$. Second, we assume that firm 2 requires no outside funds $\left(\mathrm{I}_{2}=0\right)$, so that only firm 1 has a non-trivial choice among financing sources.

Although we are certain that the types of effects that we examine in the simplified model will carry over into more general treatments, our main justification for considering the specialized model is that we are yet at an exploratory stage. We have yet to analyze the more general model, and we will make little attempt to speculate about which of our results generalize.

\section{The model without debt}


As a benchmark, it is helpful to present the model without debt. Here we consider two cases, the full information case--where each firm knows its competitor's costs--and the private information case--where each firm knows only its own costs. This section reproduces the results of Gal-Or (1986), Shapiro (1986), and others, who show that internally financed Cournot competitors will wish to precommit to share private information about an idiosyncratic cost (or demand) shock.

\subsection{Full information}

Under full information, given cost realization $\mathrm{c}_{1}$, firm 1 chooses its output level to maximize,

$$
\pi_{1}^{*}\left(c_{1}\right)=\varphi R_{1}^{*}\left(c_{1}, a_{g}\right)+(1-\varphi) R_{1}^{*}\left(c_{1}, a_{b}\right)
$$

Firm 2 maximizes a similar expression. Maximizing, and solving, we find that:

$$
q_{1}^{*}\left(c_{1}\right)=\frac{a^{e}+c_{2}-2 c_{1}}{3}, q_{2}^{*}(c)=\frac{a^{e}+c_{1}-2 c_{2}}{3},
$$

where $\mathrm{a}^{\mathrm{e}} \equiv \varphi \mathrm{a}_{\mathrm{g}}+(1-\varphi) \mathrm{a}_{\mathrm{b}}$ and $\mathrm{c}_{1} \in\{0, \mathrm{c}\}$. Firm 1's period 0 expected profits are,

$$
\mathrm{E}\left[\pi^{*}{ }_{1}\left(\mathrm{c}_{1}\right)\right]=\mathrm{p} \pi_{1}^{*}(0)+(1-\mathrm{p}) \pi_{1}^{*}(\mathrm{c})
$$

and substituting (1) and (2) into the profit expression, we have

$$
E_{c_{1}}\left[\pi_{1}^{*}\left(c_{1}\right)\right]=p\left[q_{1}^{*}(0)\right]^{2}+(1-p)\left[q_{1}^{*}(c)\right]^{2} .
$$

\subsection{Private information}


Unlike the public information case, firm 2 makes its output decision without knowing firm 1's costs or output. In this case,

$$
q_{1}^{b}\left(c_{1}\right)=\frac{2 a^{e}-c^{e}+2 c_{2}-4 c_{1}}{6}, \quad q_{2}^{b}\left(c_{1}\right)=\frac{a^{e}+c^{e}-2 c_{2}}{3},
$$

where,

$$
c^{\mathrm{e}} \equiv(1-\mathrm{p}) \mathrm{c},
$$

which is firm 1's expected cost. The important feature to note about the expressions in (4) is that firm 1's expected cost, rather than its realized cost, determines firm 2's output choice.

Comparing firm 2's strategies in the full information and private information cases, we see that,

$$
\mathrm{q}_{2}^{*}(\mathrm{c})<\mathrm{q}_{2}^{\mathrm{b}}\left(\mathrm{c}_{1}\right)<\mathrm{q}_{2}^{*}(0) \text {. }
$$

Since firm 2 cannot observe firm 1's cost, the firm cannot tailor the aggressiveness of its output strategy to firm 1's competitive strength. Similarly, we see that,

$$
\mathrm{q}^{*}{ }_{1}(0)<\mathrm{q}_{1}^{\mathrm{b}}(0) \text {, and } \mathrm{q}_{1}^{*}(\mathrm{c})>\mathrm{q}_{1}^{\mathrm{b}}(\mathrm{c}) \text {. }
$$

Intuitively, under private information, firm 1 knows that firm 2 cannot tailor its output strategy to firm 1's competitive strength. In turn, firm 1 cannot respond as aggressively when its own costs are low and must respond more aggressively when its own costs are high.

In the private information case, firm 1's profits can be written,

$$
E_{c_{1}}\left[\pi_{1}^{b}\left(c_{1}\right)\right]=p\left[q_{1}^{b}(0)\right]^{2}+(1-p)\left[q_{1}^{b}(c)\right]^{2}
$$

\subsection{Comparing the two cases}


Subtracting expression (5) from (3) we find that firm 1 will always choose to commit to communicate information about its own costs--if it can do so. We write this result, which is just a specialized variant of Gal-Or (1986) and Shapiro (1986), as Lemma 1, because it will be useful later. The proof of this result and all succeeding results are in the Appendix.

Lemma 1: Firm 1's expected profits are higher when it communicates information about its costs than when it keeps this information confidential:

$$
\Delta^{* b} \equiv E_{c_{1}}\left[\pi_{1}^{*}\left(c_{1}\right)\right]-E_{c_{1}}\left[\pi_{1}^{b}\left(c_{1}\right)\right]=\frac{7 c^{2} p(1-p)}{36}>0
$$

The intuition behind Lemma 1 is that communication between the competitors allows them to coordinate their strategies in a particular way; communication induces more negative correlation in the competitors' output strategies. When firm 1's costs are low and this is communicated to firm 2, firm 2 responds by choosing very low output levels--thereby increasing firm 1's profits. When firm 1's costs are high and this is communicated to firm 2, firm 2 responds by choosing very high output levels--thereby reducing firm 1's profits. The net effect on firm 1's profits is positive because the two firms compete in strategic substitutes: The firm's marginal return to increasing output is highest when its competitor's output is lowest. By communicating information, firm 1 induces firm 2 to decrease output in states where firm 1's marginal return to higher output is greatest and to increase output in states where firm 1's marginal return to higher output is smallest.

For later reference, it is useful to look at the comparative statics of Lemma 1. First, 
communication is relatively more valuable when $\mathrm{c}$ is higher, that is, when the difference in marginal costs between high and low cost states is higher. Intuitively, when this difference is higher, the marginal return to inducing more negative correlation in the competitors' strategies is higher. Second, the marginal return to communication is highest when $\mathrm{p}=1 / 2-$-when prior uncertainty about firm 1's costs is at a maximum-- and falls continuously as $\mathrm{p}$ approaches either 0 or 1. In either case, as prior uncertainty about firm 1's costs falls, the benefits of coordination through communication also falls. Thus, we have,

\section{Lemma 2:}

$$
\frac{d \Delta^{* b}}{d c}>0, \quad \frac{d \Delta^{* b}}{d p}>0(<0) \Leftrightarrow p<\frac{1}{2}\left(>\frac{1}{2}\right)
$$

\section{Loans Versus Bonds}

This section contains our main results. To date, we have complete comparative statics for only a portion of the parameter space. For this portion of the parameter space (which we characterize in more detail below) we find that the relative attractiveness of bonds compared with loans (i) increases as the probability of high market demand increases, and (ii) increases as the probability of low costs for firm 1 increases. We also find necessary conditions for loans to dominate at all.

\subsection{Bonds}

We restrict attention to cases in which (i) the bond is not always in default, and (ii) there is a positive probability of default. Otherwise there are no agency conflicts associated with 
public debt finance, and bonds clearly dominate loans by Lemma 1. These two conditions can be summarized in the double inequality,

$$
R_{1}^{p}\left(0, a_{g}\right)>D^{p}>\min \left[R_{1}^{p}\left(0, a_{b}\right), R_{1}^{p}\left(c, a_{g}\right), R_{1}^{p}\left(c, a_{b}\right)\right]
$$

In this paper, we make the further restriction that,

$$
\min \left[R_{1}^{p}\left(0, a_{b}\right), R_{1}^{p}\left(c, a_{g}\right)\right]>D_{1}^{p}>R_{1}^{p}\left(c, a_{b}\right)
$$

This says that the only default state for firm 1 is the worst state of the world, in which its costs are high and market demand is small. ${ }^{6}$ The face value of the debt, $\mathrm{D}_{1}{ }^{\mathrm{p}}$, is the solution to the problem:

$$
\begin{aligned}
\max _{D} E\left[\pi_{1}^{p}(D)\right]= & p \varphi\left[R_{1}^{p}\left(0, a_{g}\right)-D, 0\right]^{+}+p(1-\varphi)\left[R_{1}^{p}\left(0, a_{b}\right)-D, 0\right]^{+} \\
+ & (1-p) \varphi\left[R_{1}^{p}\left(c, a_{g}\right)-D, 0\right]^{+}+(1-p)(1-\varphi)\left[R_{1}^{p}\left(c, a_{b}\right)-D, 0\right]^{+},
\end{aligned}
$$

subject to:

$$
\begin{aligned}
& p \varphi\left[R_{1}^{p}\left(0, a_{g}\right), D\right]^{-}+p(1-\varphi)\left[R_{1}^{p}\left(0, a_{b}\right), D\right]^{-} \\
+ & (1-p) \varphi\left[R_{1}^{p}\left(c, a_{g}\right), D\right]^{-}+(1-p)(1-\varphi)\left[R_{1}^{b}\left(c, a_{b}\right), D\right]^{-} \geq r,
\end{aligned}
$$
model.

${ }^{6}$ Although we have studied other cases, this case presents the main forces at work in the 


$$
\begin{aligned}
& q_{1}^{p}\left(c_{1}\right)=\operatorname{argmax} \varphi\left[R_{1}^{p}\left(c_{1}, a_{g}\right)-D, 0\right]^{+}+(1-\varphi)\left[R_{1}^{p}\left(c_{1}, a_{b}\right)-D, 0\right]^{+}, \quad c_{1}=0, c \\
& q_{2}^{p}\left(c_{1}\right)=\operatorname{argmax} \varphi R_{2}^{p}\left(c_{1}, a_{g}\right)+(1-\varphi) R_{2}^{p}\left(c_{1}, a_{b}\right), \quad c_{1}=0, c
\end{aligned}
$$

and (9).

Expression (10) denotes the borrower's period 0 expected profits, and expression (11) is the participation constraint for bondholders. Expressions (12) and (13) define the equilibrium output levels chosen by the two firms, given that both firms learn firm 1's costs when firm 1 is financed by bonds. Firm 2's optimal output is simply the standard Cournot output, since we have assumed that firm 2 requires no outside funding to produce. Expression (12) spells out explicitly the limited liability effect on firm 1's output choice. The firm takes no account of its expected value in those states where bondholders take over the firm.

Imposing the inequalities in (9), the optimal output levels in (12) and (13) can be derived:

$$
q_{1}^{p}(0)=\frac{a^{e}+c_{2}}{3}, \quad q_{1}^{p}(c)=\frac{a_{g}+c_{2}-2 c}{3},
$$

and

$$
q_{2}^{p}(0)=\frac{a^{e}-2 c_{2}}{3} \quad, \quad q_{2}^{p}(c)=\frac{2 a^{e}-a_{g}+c-2 c_{2}}{3} .
$$


Two points should be noted about (14) and (15). First, since firm 1 never defaults when its costs are low--by assumption (9)--the output level chosen when $\mathrm{c}_{1}=0$ is identical to the level that would be chosen if the firm were self-financed. Thus,

$$
q_{1}^{p}(0)=q_{1}^{*}(0) \quad, \quad q_{2}^{p}(0)=q_{2}^{*}(0)
$$

Second, since firm 1 defaults when costs are high and demand is low--again by assumption (9)-the limited liability effect induces the firm 1 to choose higher output levels than when the firm is self-financed. Thus,

$$
q_{1}^{p}(c)>q_{1}^{*}(c) \quad, \quad q_{2}^{p}(c)<q_{2}^{*}(c)
$$

Substituting (11) into (10), and (14) and (15) into the resulting expression, and using assumption (9), the borrower's maximized profits under the bond contract can be written:

$$
E\left[\pi_{1}^{p}\left(D_{1}^{p}\right)\right]=p\left[a^{e}-Q^{p}(0)\right] q_{1}^{p}(0)+(1-p)\left[a^{e}-Q^{p}(c)-c\right] q_{1}^{p}(c)-r
$$

where $\mathrm{Q}^{\mathrm{p}}\left(\mathrm{c}_{1}\right)$ denotes the total market output when firm 1 has costs $\mathrm{c}_{1}$. This can be rewritten,

$$
E\left[\pi_{1}^{p}\left(D_{1}^{p}\right)\right]=p\left[q_{1}^{p}(0)\right]^{2}+(1-p)\left[q_{1}^{p}(c)-\left(a^{e}-a_{g}\right)\right] q_{1}^{p}(c)-r
$$

Expression (19) follows immediately from (18) by substituting (14) and (15) into (18). We will return to expression (19) shortly. 


\subsection{Loans}

Given our simplifying assumption that the firm breaches the restrictive covenant whenever its costs are high, only two possible cases remain. Either firm 1 never defaults when its costs are low or it defaults when its costs are low and market demand is low. We consider the first case, that is,

$$
R_{1}^{b}\left(0, c_{b}\right)>D_{1}^{b}
$$

The face value of the debt is the solution to the problem:

$$
\max _{D}\left[E \pi_{1}^{b}(D)\right]=p \varphi\left[R_{1}^{b}\left(0, a_{g}\right)-D, 0\right]^{+}+p(1-\varphi)\left[R_{1}^{b}\left(0, a_{b}\right)-D, 0\right]^{+}
$$

subject to,

$$
\begin{aligned}
& p\left(\varphi\left[R_{1}^{b}\left(0, a_{g}\right), D\right]^{-}+(1-\varphi)\left[R_{1}^{b}\left(0, a_{b}\right), D\right]\right)^{-}+(1-p)\left(\varphi R_{1}^{b}\left(c, a_{g}\right)+(1-\varphi) R_{1}^{b}\left(c, a_{b}\right)\right) \geq r \\
& q_{1}^{b}(0)=\operatorname{argmax} \varphi\left[R_{1}^{b}\left(0, a_{g}\right)-D, 0\right]^{+}+(1-\varphi)\left[R_{1}^{b}\left(0, a_{b}\right)-D, 0\right]^{+}, \\
& q_{1}^{b}(c)=\operatorname{argmax} \varphi R_{1}^{b}\left(c, a_{g}\right)+(1-\varphi) R_{1}^{b}\left(c, a_{b}\right), \\
& q_{2}^{b}(0)=q_{2}^{b}(c)=\operatorname{argmax} E_{c_{1} a}\left[R_{2}^{b}\left(c_{1}, a\right)\right],
\end{aligned}
$$

and (20). 
Equation (21)--firm 1's expected profits--and equation (22)--the bank's participation constraint--both incorporate our assumption that firm 1 is in breach of contract when its costs are high and that the bank is a monopolist in the bargaining game when the firm is in breach. Expressions (23) and (24) are written to highlight the essential difference between firm 1's quantity choice when the firm is in breach of contract and when it is in compliance. When the firm is in breach--expression (24)--the bank's control overcomes agency problems that would otherwise arise, and the firm chooses the level of output that maximizes the firm's value. ${ }^{7}$ When the firm is not in breach--expression (23)--it makes output decisions to maximize the firm's value in non-default states. (In our example, there is no default when the firm's costs are low.) Expression (25) displays firm 2's output decision, which must be made on the basis of firm 1's expected costs because of the confidentiality of bank debt.

In light of parametric restriction (20)--which ensures that there are no agency conflicts when the firm's costs are low--and since firm 1 chooses the level of output that maximizes the firm's and the bank's joint profits when the covenant has been breached, we see that firm 1 chooses the same level of output that would be chosen by a self-financed firm. That the loanfinanced firm chooses a level of output identical to one in a market without debt is, of course, an artifact of some of our simplifying assumptions and parametric restrictions. Nonetheless, the underlying idea will carry over to more general treatments.

Then, it is straightforward to solve (23)- (25):

${ }^{7}$ Of course, one can easily imagine more complicated bargaining games in which bargaining does not always lead to a joint maximizing output choice. 


$$
q_{1}^{b}(0)=\frac{2 a^{e}+c^{e}-c_{2}}{6} \quad, \quad q_{1}^{b}(c)=\frac{2 a^{e}+c^{e}-c_{2}-4 c}{6},
$$

and

$$
q_{2}^{b}(0)=q_{2}^{b}(c)=\frac{a^{e}+c^{e}-2 c_{2}}{3}
$$

which are the output levels already derived in Section 2 for the private information model without debt.

\subsection{Comparing loans and bonds}

Since only firm 1 has a non-trivial financing decision to make, the market equilibrium will depend on which financing source maximizes firm 1's expected profits. Denote the difference between firm 1's profits using bonds and bank loans by,

$$
\begin{aligned}
\Delta_{1}^{p b} & \equiv E \pi_{1}^{p}\left(D_{1}^{p}\right)-E \pi_{1}^{b}\left(D_{1}^{b}\right) \\
& =\left(p\left[q_{1}^{p}(0)\right]^{2}+(1-p)\left[q_{1}^{p}(c)-\left(a^{e}-a_{g}\right)\right] q_{1}^{p}(c)\right) \\
& -\left(p\left[q_{1}^{b}(0)\right]^{2}+(1-p)\left[q_{1}^{b}(c)\right]^{2}\right),
\end{aligned}
$$

where we have used (5) and (19). Bonds are chosen over bank loans whenever expression (28) is positive. It will be convenient to break up $\Delta^{\mathrm{pb}}{ }_{1}$ into two components, each of which compares the 
profits of the debt-financed firm 1 of this section to its full-information, internally financed counterpart of Section 2,

$$
\Delta_{1}^{p b}=E_{c_{1}}\left(\left[\pi_{1}^{*}\left(c_{1}\right)\right]-\left[\pi_{1}^{b}\left(c_{1}\right)\right]\right)-E_{c_{1}}\left(\left[\pi_{1}^{*}\left(c_{1}\right)\right]-\left[\pi_{1}^{p} c_{1}\right]\right)=\Delta_{1}^{* b}-\Delta_{1}^{* p}
$$

where: (i) the first term denotes the difference between firm 1's profits when it is self-financed (and information is full) and when it is loan-financed, and (ii) the second term denotes the difference between firm 1's profits when it is self-financed (and information is full) and when it is bond-financed.

Since the loan-financed firm acts exactly as if it were self-financed in a private information equilibrium, we have already calculated the first term (see Lemma 1). ${ }^{8}$ This term is always positive because the confidentiality of loans--which reduces firms' ability to coordinate around a strategy of negatively correlated outputs--imposes a cost alongside the beneficial reduction in agency problems. We calculate the second term in the following lemma:

\section{Lemma 3:}

$$
\Delta_{1}^{* p}=(1-p)\left(\frac{a_{g}-a^{e}}{3}\right)\left[2\left(\frac{a_{g}-a^{e}}{3}\right)-q^{*}(c)\right]
$$

Expression (30) can be either positive or negative, depending on the sign of the third term in brackets. (Note that the second bracketed term is always positive.) There are two underlying

${ }^{8}$ Note that we have ignored the financing cost term, r. If we imagine that the internally financed firm must make the same investment $\mathrm{I}_{\mathrm{j}}$, it would use $\mathrm{r}$ as the opportunity cost of funds. 
effects. First, there is a competitive effect, whereby a bond-financed firm 1 captures profits at the expense of firm 2 by committing to a more aggressive output strategy than it would if it were internally financed. Second, there is an agency effect, whereby a bond-financed firm 1 increases its borrowing costs because its output choice ignores the firm's value in default states. Which of the two effects dominates depends on the size of the debt-induced distortion from the valuemaximizing output choice (relative to output). This distortion is proportional to the difference between the intercept of the demand curve in the good state alone and the expected value of the demand intercept $\left(a_{g}-a^{e}\right)$.

Putting (6) and (30) together we have,

Proposition 1. Firm 1 chooses bond financing if and only if $\Delta_{1}^{\mathrm{pb}}>0$, where

$$
\Delta_{1}^{p b}=\frac{7 c^{2} p(1-p)}{36}-(1-p)\left(\frac{a_{g}-a^{e}}{3}\right)\left[2\left(\frac{a_{g}-a^{e}}{3}\right)-q^{*}(c)\right] .
$$

One immediate implication of Proposition 1 is that for a sufficiently small agency effect -as measured by $\left(a_{\mathrm{g}}-\mathrm{a}^{\mathrm{e}}\right)$--bonds must dominate loans. This follows because we know that the confidentiality effect, measured by the first term in (31), is always positive. That is, firms prefer to share information in our model. In turn, if the competitive effect is greater than the agency effect, that is, if $\Delta_{1}{ }^{*} \mathrm{p}<0$, bonds strictly dominate loans. From now on, we restrict attention to the case in which loans might dominate, that is, $\Delta_{1}{ }^{*} \mathrm{p} \geq 0$.

We now turn to our main comparative statics results.

\section{Proposition 2}




$$
\begin{array}{ll}
\text { (i) } \Delta_{1}^{* p}(\varphi) \geq 0 & \Rightarrow \frac{d \Delta_{1}^{p b}(\varphi)}{d \varphi}>0, \\
\text { (ii) } \Delta_{1}^{p b}\left(p^{*}\right)=0 & \Rightarrow \Delta_{1}^{p b}(p)<0(\geq 0) \quad \Leftrightarrow \quad p<p^{*}\left(\geq p^{*}\right) .
\end{array}
$$

Both parts of Proposition 2 have straightforward interpretations. Expression (32.i) says that bonds become more attractive as the likelihood of high market demand increases. Intuitively, the bond-financed firm's output distortion in high cost states declines as the probability of high market demand increases (and $\mathrm{a}^{\mathrm{e}} \rightarrow \mathrm{a}_{\mathrm{g}}$ ). In turn, lender control over the firm's output choice when its incentives are distorted becomes more valuable.

Expression (32.ii) says that loans will be chosen when the probability of low costs is low and that bonds will be chosen when the probability of low costs is high. Intuitively, the benefits of greater control over the borrower's behavior through loan covenants are greatest when costs are likely to be high and, in turn, agency problems are most severe. So, for low values of $\mathrm{p}$, firm 1 chooses loans over bonds.

\section{Conclusion}

In this paper we have examined a firm's choice between private and public debt in a model where financing choice affects product market competition. The terms of the tradeoff are defined by two effects. Private debt places controls over a borrowing firm's output decisions in states where covenants are breached. This monitoring effect favors private debt over public debt. Private debt maintains confidentiality, while public debt forces firms to make private information 
public both to its investors and its competitors. This confidentiality effect favors public debt over private debt in a Cournot oligopoly, in which firms prefer to share firm-specific information with their competitors.

We have three main findings. First, we find the deviation between high and low demand states must be large for private debt to dominate public debt. Second, we find that public debt becomes relatively more profitable as the probability of high market demand increases. Third, we find that public debt becomes relatively more profitable as the probability of technical progress (leading to low costs) increases. 


\section{Appendix}

\section{Proof of Lemma 1:}

Subtracting (5) from (3), we can see that,

$$
\Delta_{q}^{* b}=p\left[q_{1}^{*}(0)-q_{1}^{b}(0)\right]+(1-p)\left[q_{1}^{*}(c)-q_{1}^{b}(c)\right]
$$

Then using (2) and (4), and denoting $\left(\mathrm{c}_{1}-\mathrm{c}^{\mathrm{e}}\right) / 6$ by $\mathrm{z}\left(\mathrm{c}_{1}\right)$,

$$
q_{1}^{b}\left(c_{1}\right)=q_{1}^{*}\left(c_{1}\right)+\frac{c_{1}-c^{e}}{6}=q_{1}^{*}\left(c_{1}\right)+z\left(c_{1}\right)
$$

and substituting (34) into (33),

$$
\Delta_{1}^{* b}=-p z(0)\left[2 q_{1}^{*}(0)+z(0)\right]-(1-p) z(c)\left[2 q_{1}^{*}(c)+z(c)\right]
$$

Then substituting in the values for $\mathrm{q}_{1}{ }^{*}\left(\mathrm{c}_{1}\right)$ and $\mathrm{z}\left(\mathrm{c}_{1}\right)$, inequality (6) follows immediately.

\section{Proof of Lemma 2:}

The two derivatives in (7) are immediate.

\section{Proof of Lemma 3:}

Since a firm with public debt chooses the first best output level when $\mathrm{c}_{1}=0$, the only difference in the profits between a self-financed firm and a firm financed with public debt occurs when $\mathrm{c}_{1}=\mathrm{c}$. Thus, 
$\Delta_{1}^{* p}=(1-p)\left[q_{1}^{*}(c)^{2}-\left(q_{1}^{p}(c)-\left(a_{g}-a^{e}\right)\right) q_{1}^{p}(c)\right]$.

From (4) and (14) we have,

$q_{1}^{p}(c)=q_{1}^{*}(c)+\frac{2\left(a_{g}-a^{e}\right)}{3}$,

and substituting (37) into (36), expression (30) follows immediately.

\section{Proof of Proposition 1:}

Proposition 1 follows immediately from substituting (6) and (30) into (29).

\section{Proof of Proposition 2:}

Define $\delta^{* \mathrm{k}}=(1-\mathrm{p})^{-1} \Delta^{* \mathrm{k}}$, where $\mathrm{k}=\mathrm{p}, \mathrm{b}$. Then,

$$
\Delta^{p b}(p)=(1-p)\left[\delta^{* b}(p)-\delta^{* p}\right],
$$

using (29). The notation makes clear that $\delta^{* \mathrm{p}}$ is independent of $\mathrm{p}$. By assumption, $\delta^{* \mathrm{p}}>0$, so simple inspection of (31) shows that

$$
\Delta^{p b}(0)<0, \quad \Delta^{p b}(1)=1 .
$$

Differentiating (38) with respect to $\mathrm{p}$, 
$\frac{d \Delta^{p b}}{d p}=-\left[\delta^{* b}-\delta^{* p}\right]+(1-p) \frac{d \delta^{* b}}{d p}$.

and differentiating again,

$$
\frac{d^{2} \Delta^{p b}}{d p^{2}}=-2 \frac{d \delta^{* b}}{d p}-p \frac{d^{2} \delta^{* b}}{d p^{2}}
$$

It is immediate from the definition of $\delta^{* b}$ that

$$
\frac{d \delta^{* b}}{d p}>0, \quad \frac{d^{2} \delta^{* b}}{d p^{2}}=0
$$

so from (41), $\Delta^{\mathrm{pb}}$ is concave in $\mathrm{p}$. The concavity of $\Delta^{\mathrm{pb}}$ in $\mathrm{p}$ and (39) imply that $\Delta^{\mathrm{pb}}$ can equal 0 for at most one value of $\mathrm{p}$ on the interval $[0,1)$. At this value, say $\mathrm{p}^{*}$, we can evaluate (40),

$$
\frac{d \Delta^{p b}\left(p^{*}\right)}{d p}=\left(1-p^{*}\right) \frac{d \Delta^{* b}}{d p}>0 .
$$

So for all values of $\mathrm{p}<\mathrm{p}^{*}$ loans dominate and for all values of $\mathrm{p}>\mathrm{p}^{*}$ bonds dominate (until $\mathrm{p}=$ 1). This proves (32.ii).

Since inspection of (31) shows that $\delta^{* b}$ is independent of $\varphi$, we can differentiate (38) to show that, 
$\frac{d \Delta^{p b}(\varphi)}{d \varphi}=-(1-p) \frac{d \delta^{* p}(\varphi)}{d \varphi}$

Let $\left(a_{g}-a^{e}\right) / 3=y(\varphi)$. Then, evaluating (44)

$$
\frac{d \delta^{* p}(\varphi)}{d \varphi}=\frac{d y}{d \varphi}\left(2 y-q^{*}(c)\right)+y\left(2 \frac{d y}{d \varphi}-\frac{d q^{*}(c)}{d \varphi}\right)
$$

and noting that $\mathrm{dy} / \mathrm{d} \varphi=-\mathrm{dq}^{*}(\mathrm{c}) / \mathrm{d} \varphi$ (using (2) and the definition of $\mathrm{y}$ ), we can rewrite (45),

$$
\frac{d \delta^{* p}(\varphi)}{d \varphi}=\frac{d y}{d \varphi}\left(2 y-q^{*}(c)\right)+y\left(2 \frac{d y}{d \varphi}+\frac{d y}{d \varphi}\right)<0
$$

where the inequality follows from $d y / d \varphi=-(1 / 3)\left(a_{g}-a_{b}\right)$ and our assumption that $\delta^{* p}>0$. Expression (32.i) then follows immediately from (44). 


\section{References}

Bhattacharya S., and G. Chiesa, "Proprietary Information, Financial Intermediation, and Research Incentives," Journal of Financial Intermediation, 4, 4 (October 1995), pp. 328357.

Bhattacharya, S., and A. Thakor, “Contemporary Banking Theory,” Journal of Financial Intermediation, 3,1 (October 1993) pp. 2-50.

Brander, J., and T. Lewis, “Oligopoly and Financial Structure: The Limited Liability Effect," American Economic Review, 76, (December 1986), pp. 956-970.

Campbell, T., "Optimal Investment Financing Decisions and the Value of Confidentiality," Journal of Financial and Quantitative Analysis, 14,5 (December 1979), pp. 913-924.

Gal-Or, E., "Information Transmission--Cournot and Bertrand Equilibria," Review of Economic Studies, 53, (January 1986), pp.85-92.

Shapiro, C., "Exchange of Cost Information in Oligopoly," Review of Economic Studies, 53, (July 1986), pp.443-446.

Vives, X., “Duopoly Information Equilibrium: Cournot and Bertrand,” Journal of Economic Theory, 34, (June 1985), pp. 71-94.

Yosha, O., "Information Disclosure Costs and the Choice of Financing Source," Journal of Financial Intermediation, 4,1, (January 1995), pp. 3-20. 